\title{
Forward hedging under price and production risk of wheat
}

\author{
Xing Liu and Kyösti Pietola \\ Agrifood Research Finland, Economic Research, Helsinki, Finland. \\ Correspondence to:xing.liu@mtt.fi kyosti.pietola@mtt.fi
}

\section{Introduction}

A quite large literature focuses on optimal hedging problems in the futures markets (see e.g., Tomek and Peterson, 2001; Lapan and Moschini, 1994). The standard in the studies on optimal hedging is that market is efficient such that the futures contract is allowed to be offset (liquidated) by an opposite contract before its maturity. The hedging problem of Myers and Thompson (1989) is also truly dynamic such that it allows for continuous adjustment in the hedging position.

A problem on generalizing these results to Finland is that the short run grain price movements may not be fully integrated to other markets, in which also the futures are traded (Kola and Taipale 2000). Another problem is that independent grain producers may not have a direct access to the derivatives market since transactions costs for entering these markets are too high for them. A "full" hedge, which is a combination of futures contracts and sales of put options is not feasible. Nevertheless, they can usually enter in a forward contract with a local grain dealer. In Finland, for example, Avena Nordic Grain (Avena) has offered forward contracts for the Finnish grain producers since the year 2000. In these contracts, the buyer (seller) is obligated to purchase (deliver) grains from (to) Avena at the agreed maturity date in the future at the fixed price.

The hedging problem of the Finnish grain producer is, at least for two reasons, a special and restricted version of the problems generally studied in the literature. First, the forward contract, they have access to, is incomplete compared to the liquid and highly standardized futures contracts. The non-tradable forward contract is irreversible and can only be terminated by the delivery. Therefore, there is no basis risk and potential for pure speculation is negligible. Second, in the Northern wheat producing areas yield uncertainty is large, which moves weight from the price volatility to the yield volatility in the optimal hedging problem.

The goal of this paper is to estimate optimal hedging ratios for Finish spring wheat producers. Optimal hedging ratio is defined as the share of the expected yield sold through a forward contract. The contract is signed at sowing time for a fixed price and quantity, delivered at harvest. We solve the hedging problem by an Expected Variance model (EV) and take into the comparisons also the Expected Utility model (EU), first derived into a similar hedging problem by Lapan and Moshini (1994).

The analysis focuses on a spring wheat producer located in the Southwest of Finland. The hedging and production decisions are made in April/May once a year, while the execution of the forward contract is performed in August of the same year. Therefore, we take $21^{\text {st }}$ week of each year as the time at which production commitments are made and the forward contract is signed. Harvest and delivery take place 15 weeks later, at $36^{\text {th }}$ week of the same year. Termination of the forward contract also occurs at harvest since it can be terminated only through the delivery.

\section{The hedging model}

The EV-approach is to approximate wealth (W) by the Certainty Equivalence, defined as the difference between the expected income and the risk premium

$$
W=E(y)-\frac{1}{2} A \sigma_{y}^{2}
$$

where $\mathrm{E}(\mathrm{y})$ is the expected income and the term $\frac{1}{2} A \sigma_{y}^{2}$ is the Arrow-Pratt risk premium. It consists of the risk aversion coefficient, $A$, and from the variance of income, $\sigma_{y}^{2}$. If the variance of income increases at a given income level, wealth decreases because $A>0$.

Let $\tilde{p}$ denote the stochastic wheat price, $\widetilde{q}$ the stochastic yield, and $h$ the forward sale at the harvest per hectare at a fixed price $p_{f}$. The remaining output $(\widetilde{q}-h)$ is sold at the spot market price at harvest. Denoting the expected yield by $E q$, a hedge occurs when $0 \leq h \leq E q$; speculation occurs 
when $h>E q$ or when $h<0$. The farmer's income comes from two sources: the uncertain earnings from the un-hedged output $\tilde{p}[\tilde{q}-h]$ and the certain returns, $p_{f} h$, from the output sold in the forward contract. Then, farmer income at harvest is

$$
y=\tilde{p}[(\widetilde{q}-h)]+p_{f} h=\tilde{p} \widetilde{q}+h\left(p_{f}-\tilde{p}\right)
$$

and the expected income is:

$$
E(y)=E(\tilde{p} \tilde{q})+h\left(p_{f}-E p\right)
$$

where $E(\tilde{p} \widetilde{q})$ is the expected value of joint normally distributed price and yield. $E p$ is the expected price. Variance of income $\sigma_{y}^{2}$ is:

$$
\sigma_{y}^{2}=\sigma_{p q}^{2}+h^{2} \sigma_{p}^{2}-2 h \operatorname{cov}(\tilde{p}, \tilde{p} \widetilde{q})
$$

where $\sigma_{p q}^{2}$ is the variance of the product of the random price and yield, $\tilde{p} \widetilde{q}$, and $\operatorname{cov}(\tilde{p}, \tilde{p} \widetilde{q})$ is the covariance between $\widetilde{p}$ and $\widetilde{p} \widetilde{q}$.

Equations (1), (2) and (4) can be solved for the optimal hedging ratio $(h / q)$.

$$
\frac{h_{1}}{E q}=\left(1+\frac{E p}{E q} r \sigma_{q} / \sigma_{p}\right)+\frac{p_{f}-E p}{A E q \sigma_{p}^{2}}
$$

which includes two components: "the hedging component" and "the speculative component". The speculative component is zero and drops out from the problem if either the forward market is unbiased $\left(p_{f}=E p\right)$, or the producer is infinitely risk averse $(\mathrm{A} \rightarrow \infty)$. If, in addition, either the price is independent from the yield $(r=0)$, or the yield risk is zero $\left(\sigma_{q}=0\right)$, the producer sells all of his expected yield through the forward contract $(h=E q)$.

When the forward price is an unbiased estimate for the price at harvest, the speculative component drops out and the optimal hedge under yield uncertainty depends on the conditional forecast for the harvest price $(E p)$, expected yield $(E q)$; volatility of the price and yield at harvest $\left(\sigma_{p}\right.$ and $\left.\sigma_{q}\right)$; and correlation between the price and the yield $(r)$. Among them, the correlation between the price and the yield is crucial for determining the optimal hedging strategy. When the correlation tends to zero, EV model suggests that the hedge ratio approaches to unity regardless of farmer's risk attitude. However, Lapan and Moschini (1994) found in their EU-model that the optimal hedge, in general, is less than the expected yield even when the price is independent from the yield.

\section{Econometric models}

The expected price at harvest and its volatility are estimated in an AutoRegressive (AR) model for the wheat price. The expected yield and the yield uncertainty are estimated using the annual data from 1995 to 2001 included in the MTT experimental trials. The correlation between the price and the yield is estimated using the error terms of the price and yield equations.

\section{Data}

The weekly data on wheat cash (spot) price are obtained from information centre of the Ministry of Agriculture and Forestry (TIKE). The price series spans from January 1995 to $21^{\text {th }}$ week of 2002 . The original price series consist of 370 observations. The price reported in the data is the price at the warehouse of buyers, i.e. the price of the raw material to the buyer. Growing seasons are 15 weeks and they are dated from the $22^{\text {nd }}$ week of the year to the $36^{\text {th }}$ week of the year.

The forward contracts are those offered by Avenakauppa and they are available for 2001 and 2002. These contracts are not tradable and they are always terminated by the delivery of the good. No penalty is imposed if farmer's yield is lower than expected and he can not deliver the good as much as agreed in the contract. Nevertheless, speculation through deliberate short selling is not allowed. The terms related to delivering the goods as much as agreed are for the most part based on trust. Avenakauppa also publishes its forward prices publicly on internet and page 747 in the text-tv of MTV3 in Finland. 
The annual yield data of spring wheat are from Agrifood Research Finland (MTT) and they span the years from 1995 to 2001 . The yield data are based on experimental trials and they are conditional on different nitrogen applications $(70-120 \mathrm{~kg} / \mathrm{ha})$. The trials have been located in the Southwest Finland, where most of the wheat production takes place.

\section{Results}

The correlation between the price and the yield was estimated at -0.36 , but the correlation does not differ significantly from zero (Table 1). The result suggests that the domestic yield does not have significant effect on the wheat price in Finland. Therefore, the EV model suggests that the optimal hedge ratio is close to unity. i.e. the expected yield should be sold through the forward market.

The corresponding EU model indicates, however, lower hedging ratios than the EV-model (Table 2). The amount of forward sale clearly declines as risk aversion increases, i.e. the more risk averse farmer, the less he is willing to sell through the forward contract. More importantly, the optimal hedge ratio decreases as the production risk increases.

Table 1. Summary of the estimated parameters.

\begin{tabular}{|l|l|}
\hline Parameters & \\
\hline Correlation between the price and the yield $(r)$ & $-0.36(0.427)$ \\
Volatility of the price at harvest $\left(\sigma_{p}\right)$ & 2.18 \\
Yield volatility $\left(\sigma_{q}\right)$ & 0.96 \\
Expected price at harvest, euro $/ 1,000 \mathrm{~kg}(E p)$ & 129.84 \\
Price at the forward contract euro/1,000 kg $\left(p_{f}\right)$ & 135 \\
Expected yield $(E q) 1,000 \mathrm{~kg}$ & 3.52 \\
\hline
\end{tabular}

Note: (.) is p-value of Pearson's correlation test.

Table 2. Optimal hedge ratios in an unbiased forward market as suggested by the EV-and EU-models conditional on $\mathrm{r}=0$ and alternative values for the coefficient of absolute risk aversion (A).

\begin{tabular}{|lcc|}
\hline A & EV-model & EU-model \\
\hline 0.002 & 1 & 0.93 \\
0.004 & 1 & 0.86 \\
0.006 & 1 & 0.80 \\
0.008 & 1 & 0.73 \\
0.01 & 1 & 0.67 \\
0.02 & 1 & 0.32 \\
\hline
\end{tabular}

\section{Concluding discussion}

Both EV and EU model suggest that the correlation coefficient between the yield and the price play a crucial role in deciding the optimal hedge ratio. Empirically, the yield and the price of a crop should be negative correlated, because total demand of food changes only moderately from year to year, while supply exhibits large annual shocks. The negative covariance between the price and the yield creates a partial "natural hedge"1, which weakens the role the forward contracts (ceteris paribus). When the natural hedge takes place, the optimal hedge is always less than expected output. In addition, hedging effectiveness declines further as yield variability increases. If the high natural hedge and high yield volatility take place simultaneously, forward sale may not be an attractive risk instrument any more if the producer does not have access to other derivatives, such as options.

Since our empirical results weakly signals for a large negative correlation between the price and the yield, we simulated the EV-model conditional on alternative values for yield volatility and the correlation coefficient between the yield and the price. Figure 1 shows that the hedge ratio is a decreasing function of yield volatility and an increasing function of correlation coefficient. For instance,

\footnotetext{
${ }^{1}$ A negative yield-price correlation means that a farmer's income is less variable from year to year than it would be otherwise, thus being called "natural hedge".
} 
at the (insignificant) estimate -0.36 for the yield and price correlation $(r)$, the forward contract is attractive to farmer only if the volatility of yield is less than 0.2 ., i.e. less than $6 \%$ of the mean yield $(=3.52$ tonnes per hectare). Otherwise forward contract is attractive only if speculation is allowed and market is biased, or the farmer also has an access to options and can complement the forward contract by selling put options (Sakong et al. 1993, Moshcini and Lapan 1995). Yield risk increases farmer incentives to trade options even when the price offered in the forward contract is an unbiased estimate for the harvest price. The reason is that a farmer who has sold his expected yield forward at a fixed price is still exposed by the risk that lower than expected yield will decrease his revenue.

When either options or crop yield insurance is available, forward contracts become more attractive to the producers (Mahul 2003). On the other hand, the European intervention program that sheds a lower bound for the wheat price and truncates the price distribution from below, decreases the optimal futures and options position in a similar fashion as highlighted by Hanson et al. (1999).

We conclude that under the Finnish production and under the European intervention programs, where the yield risk dominates the price risk, forward contracts alone do not provide sufficient means for efficient hedging. The solution to the problem is to increase farmer access to other risk derivatives such as options and further develop domestic yield insurance.

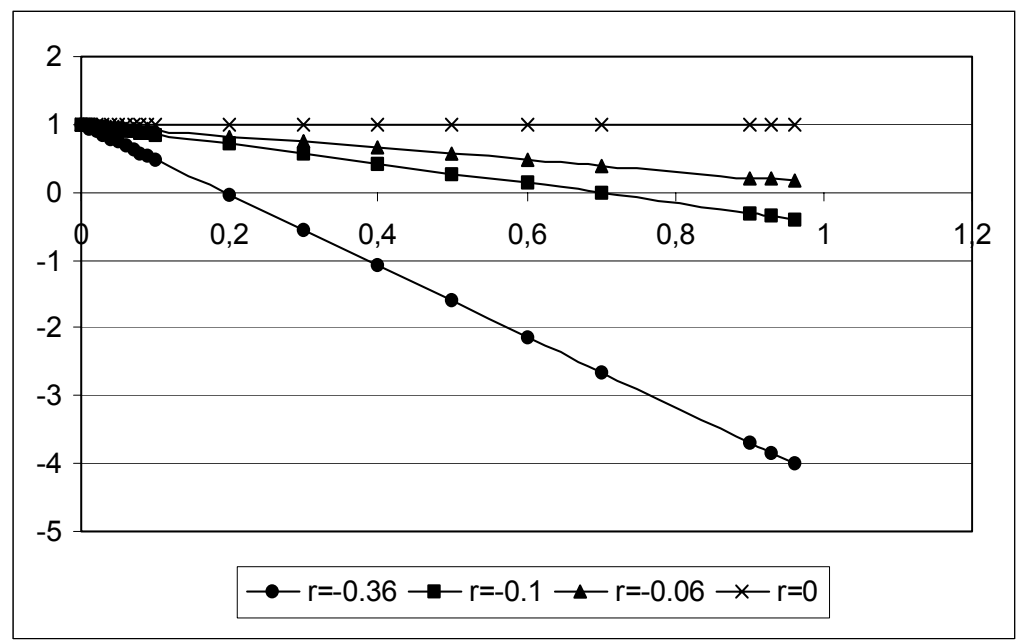

Figure. Optimal hedge ratio conditional on yield volatility and the correlation coefficient between price and yield in the EV-model.

\section{References}

Hanson. S. D. Myers R. J. and Hilker J. H. 1999. Hedging with Futures and Options under a Truncated Cash Price distribution. Journal of Agricultural and Applied Economics 31. 3: 449-459.

Kola, J. and Taipale, M. 2000. Farmers' risk management through the futures markets in the common agricultural policy of the EU - fact or fiction? Paper presented at the IAMA World Congress, Food and Agribusiness Forum Chicago, USA.

Lapan, H. and Moschini, G. 1994. Futures hedging under price, basis, and production risk. American Journal of Agricultural Economics Vol. 76: 465-77.

Mahul O. 2003. Hedging Price Risk in the Presence of Crop Yield and Revenue Insurance. European Review of Agricultural Economics Vol. 30(2). 217-239.

Moschini G. and Lapan H. 1995. The Hedging Role of Options and Futures Under Joint Price, Basis, and Production Risk. International Economic Review Vol. 36. No.4. 1025-1049.

Myers R.J. and Thompson S. R. 1989. Generalized Optimal Hedge Ratio Estimation. American Journal of Agricultural Economics 71. 858-868.

Sakong, Y., Hayes, D. J., \& Hallam, A. 1993. Hedging production risk with options. American Journal of Agricultural Economics 75, 408-415.

Tomek, W. G. and Peterson, H. H. 2001. Risk Management in Agricultural Markets: A Review. The Journal of Futures Markets Vol. 21, No. 10: 953-985. 